\title{
Design of Collaborative System of Ceramic Artworks
}

\author{
Haiying Liu, ${ }^{\mathrm{a},}$, Ronghua Lu \\ Jingdezhen Ceramic Institute, Jingdezhen 333403, China \\ ahaiyliuky@163.com, Irhlucy2003@163.com
}

\begin{abstract}
Keywords: Ceramic Raw Materials, Ceramic Auxiliary Materials, Ceramic Art Design, Porcelain Forming Process, Collaborative System, Display of Ceramic Products.
\end{abstract}

\begin{abstract}
In this paper, 72 working procedures of Jingdezhen ceramics are briefly introduced. And then this paper describes the design and realization of functional modules of collaborative system in detail, such as the information of ceramic raw and auxiliary materials, information of ceramic semi-finished and finished products, external service of ceramic kiln, display of ceramic artworks, enterprise leasing and cooperation and user management. Finally, the collaborative system of ceramic artworks based on B/S framework is implemented by using Visual Studio 2010, ASP.net, SQL Server2008 and other software.
\end{abstract}

\section{Introduction}

China is the birthplace of ceramics and Jingdezhen is famous for its ceramics. Jingdezhen ceramics rose in the Song Dynasty. It has maintained its own cultural style and artistic features for thousands of years. Jingdezhen's splendid ceramic culture and exquisite porcelain making craft attract people who love ceramics from all over the world.

With the continuous improvement of people's living standard, Chinese art is more and more popular, ceramic artworks and their market have also been developed rapidly and ceramic products are constantly innovated. But the scale of Jingdezhen ceramic manufacturing enterprises (especially for art ceramics creative enterprises) is generally not large. Typical representatives are some enterprises or workshops with dozens of people to hundreds of people, and even only a few people. Due to the small scale, these enterprises and workshops can only focus on the part of the operation in the production of ceramic artworks and can't provide collaborative information service for all kinds of entities. Therefore, the demand for exterior collaboration such as ceramic raw material, ceramic auxiliary material, ceramic semi-finished products and external service of ceramic kiln is large. Based on the above analysis, we can know that the development of the collaborative system of ceramic artworks can provide the collaborative service for the production and sale of Jingdezhen's ceramic artworks. It is conducive to the development of ceramic industry and brings benefit to ceramic production zone.

\section{System Analysis and Design}

The scientist Song Yingxing in Ming Dynasty wrote that: "ceramic making should go through 72 processes to be completed, and many details are not included in the calculation" in Tian Gong Kai Wu. In the 72 processes of Jingdezhen ceramics, there are 8 production processes, 2 modeling processes, 9 moulding processes, 29 forming processes( 12 slip casting processes, 8 drawing blank processes and 9 molding by stamping processes), 7 bisque firing processes, 8 glazing processes and 1 inspection process. There are 72 sculptures of ceramic making process in Jingdezhen City. The forming process sculpture is shown in Figure 1. 

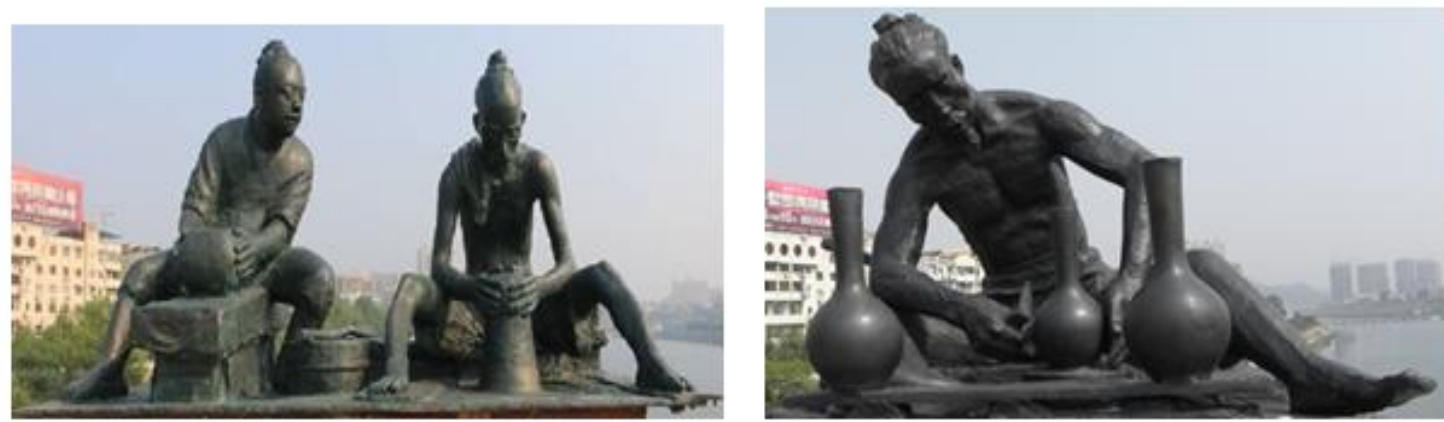

Fig 1. The display of the sculpture of forming process of ceramics

By observing and visiting the ceramic making process and art ceramics production practice in Jingdezhen, the functional modules of collaborative system of ceramic artworks are put forward, such as the information of ceramic raw and auxiliary materials, information of ceramic semi-finished products, external service of ceramic kiln, display of ceramic artworks and enterprise leasing and cooperation. The process of collaborative system of ceramic artworks is shown in Figure 2.

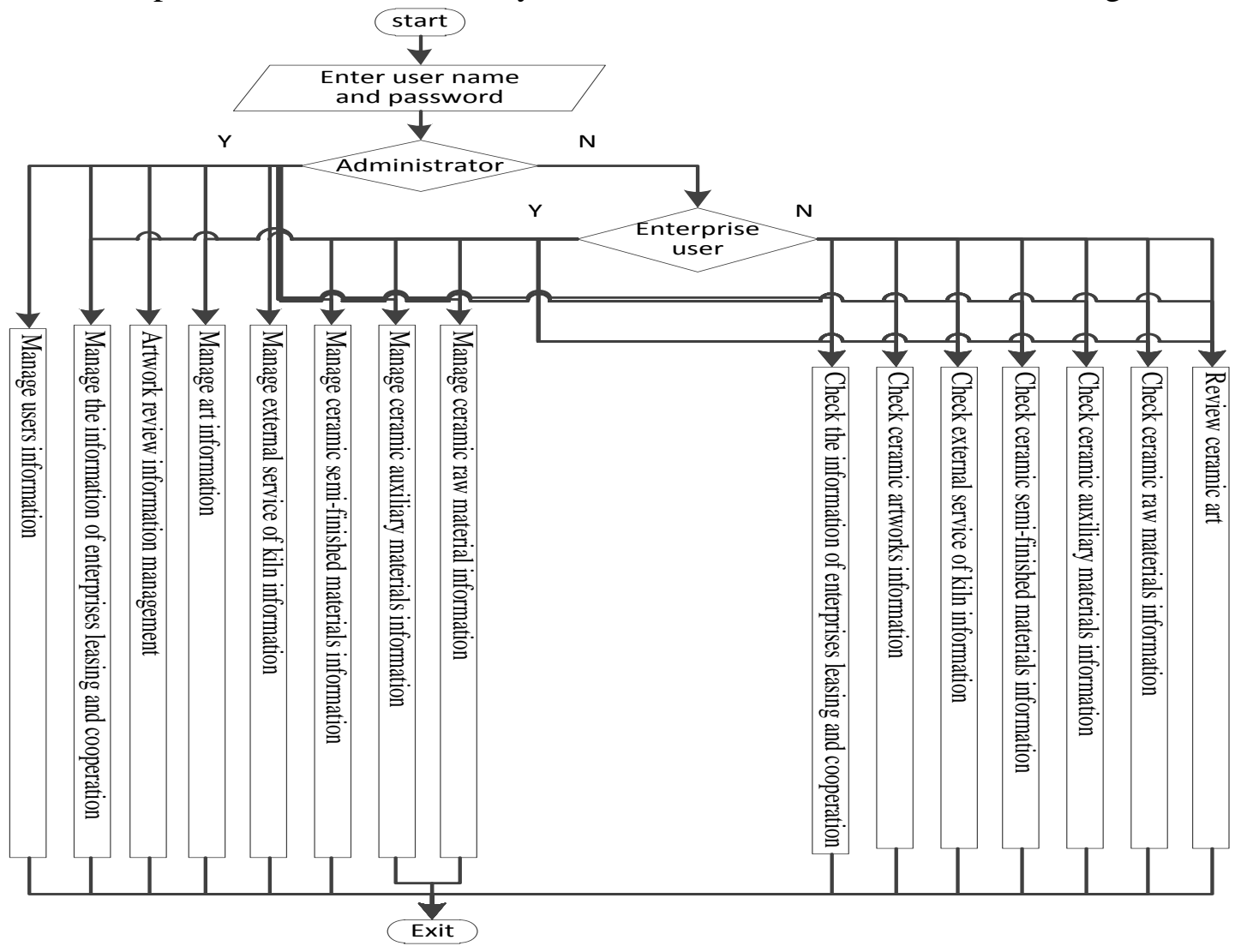

Fig 2. System flow

\section{Module Partition and Implementation of the System}

\subsection{According to the business process of ceramic production, the module function design of the} collaborative system of ceramic artworks is as follows.

\subsubsection{Ceramic making center.}

Information of ceramic raw materials: The production of ceramic artworks demands three kinds of raw materials, which are the raw materials of base (feldspar, quartz, and kaolin), raw materials of glaze (zinc oxide, magnesium oxide, etc.) and base, and glaze additive (raw material that plays a chemical or functional role in the base and glaze). This module will introduce the classification, property and main function of ceramic raw materials.

Information of ceramic auxiliary materials: Ceramic raw materials belong to exhausted resources. After nearly a thousand years of exploitation and use, it is urgent to find new alternative materials, or 
use ceramic formula technology to make use of ceramic auxiliary materials (such as ceramic waste residue). Ceramic auxiliary materials also include pigments and glazes that are never used but will be used in the future and the mould and kiln which are used to make ceramic artworks. This module will introduce and display the information of ceramic auxiliary materials.

Information of ceramic semi-finished products: Subject to the scale of the enterprise or the skills of producers, the majority of enterprises or workshops just focus on some certain procedures of ceramic production that is that some workshops just supply semi-finished ceramic products, such as base making, biscuit sale, and modulation of color glaze. In this way, both the buyer and the producer of ceramic semi-finished products are able to specialize in the ceramic making processes and links that they are good at, thus the quality and art of ceramic products can be improved and the top-quality ceramics can be launched constantly. This module will introduce and display the information of ceramic semi-finished products.

External service of ceramic kiln this is so-called "specialize in one subject", for the children of a ceramic family, they cannot complete the whole 72 work procedures of ceramics. The reality is that there are many enterprises and workshops that specialize in mold making process, forming process, glazing process, and there are few workers who are good at biscuit firing and glaze firing. Therefore, this module will introduce the types of ceramic kilns and firing characteristics of each kiln, which will help the ceramic enterprises to choose the kiln according to their needs, and then produce high-quality ceramic artworks.

\subsubsection{Display of Ceramic Products.}

The module is mainly used to display ceramic artworks. The administrator and enterprise user log in management platform to release all kinds of ceramic artworks (such as vases, sculptures, furnishings, utensils and garden ceramics). Enterprises and merchants can query and check ceramic artworks in the foreground of system, and they can leave a message, make a discussion and make a deal for the one they like.

\subsubsection{Enterprise Leasing and Cooperation.}

This module introduces the cooperation information of ceramic production enterprises, talent recruitment of ceramic enterprises, information of enterprise technology research cooperation, leasing information of ceramic shops. Through leasing and cooperation platform, the ceramic enterprises in various ceramic production areas can learn from each other, cooperate with each other and share with each other, so as to solve the difficult problems in ceramic design, production and sale, and seek new opportunities for the development and innovation of ceramic industry.

\subsubsection{User Management Module.}

In the collaborative system of ceramic art products, there are three kinds of users with different permissions, which are administrators, enterprises and merchants. The users of each permission can realize different functions: enterprises and merchants, as the main body of the system and the beneficiary, can release the information of ceramic raw and auxiliary materials, information of ceramic semi-finished products, external service information and information of enterprises leasing and cooperation, and also they can release, query, maintain and trade ceramic artworks. Administrators, as third-party users, can be independent of enterprises and merchants, mainly to complete the function of adding, deleting, checking and changing the data of various enterprises and merchants and managing users.

\subsection{System Implementation.}

The collaborative system of ceramic artworks uses the three-layered structure design based on B/S framework, in order to meet different levels of demands and services of the administrators, enterprises and merchants, and reduce the burden of the client and data server. The development environment of this system is Visual Studio 2010, ASP.net and SQL Server2008. Each functional module is mainly to realize the function of adding, deleting, checking and changing the relevant information.

The operation of adding, deleting, checking and changing the information of various ceramic raw and auxiliary materials and products in this system mainly reflect in the function of reading and 
writing background database and the display of foreground information (page). The corresponding main codes are as follows:

Code segment of information input:

Int pt=T Type. Text. Trim (); // Obtain the control value of work information category

String $\mathrm{tl}=$ Titled. Text. Trim (); // Obtain the control value of the headline of work information

String in $\mathrm{f}=$ Infom. Text. Trim (); // Obtain the control value of the content of work information

Date Time Add T = Date Time. Parse (Add Time. Text. Trim ( )); // Added time control value

Do Add In fo (pt, tl, inf, Add Time, SESSION ["adminid"]); // Add to the database

Code segment of information inquiry:

(It is assumed that we need to query the information of ceramic auxiliary materials. Its ID is 2):

Pro List plist = Bll. Get List ("id=2","id desc"); // Obtain data source

Grid View gv = new Grid View ();// Create a new Grid View object as the display source

gv. Data Source = plist; // Data source which specifies the control

gv. Data Bind (); // Binding data source

\section{Acknowledgements}

The research leading to these results has received the support of art planning project of Jiangxi province "Research on the Ceramic Art Design Based on Digital" (NO. YG2014171) and science and technology project of Jingdezhen ceramic Institute "Art and Digital Technology: Taking Art Design of Contemporary Daily Ceramics as an example", China.

\section{References}

[1]. X.M. Feng. Chinese Ceramics, Shanghai Classics Publishing House, 2001.9.

[2]. J. J. Li. Ceramic Technology, China Light Industry Press, 2006.6.

[3]. R.H. Lu. Design and Implementation of Teachers' Collaborative Office System Based on WEB, 2014 International Conference on Computational and Information Sciences, 31 May (2014): 420-425.

[4]. H. Huang. Research and Realization of the Coordination OA System based on Ceramic Profession ASP Platform. Jingdezhen Ceramic Institute of China, 2007.

[5]. H.F. Gao. Ceramic Art and Design Works Display System Design and Development, University of Electronic Science and Technology of China, 2013.

[6]. R.H. Lu. Matching and Tracking Technique Based on Time Frequency Dictionary. Applied Mechanics and Materials, Vols.513-517 (2014): 2374-2377. 